\title{
IMPROVEMENT IN WORKABILITY OF TERMINALS PLACED ALONG THE INNER SIDE OF PORT VERTICAL BREAKWATERS BY MEANS OF RECURVED PARAPET WALLS
}

\author{
PAOLO DE GIROLAMO, MYRTA CASTELLINO \& ALESSANDRO ROMANO \\ "Sapienza" University of Rome, Italy
}

\begin{abstract}
The function of main port breakwaters is to protect harbour basins from incoming waves and currents. In the event that a maritime terminal is placed on the inner side of a main breakwater, it is extremely important to limit waves overtopping the structure, because the overtopping flows may be very dangerous for the safety of the operations taking place in the terminal. Very often during storms if the overtopping discharges are severe, the terminal is temporarily closed, reducing its average annual workability accordingly. Wave overtopping is normally limited by using high parapet walls (crownwalls) which are not well considered from an environmental point of view due to their visual impact. A good solution to reduce wave overtopping limiting the increasing of the crownwalls height, is to use recurved parapet walls. The paper presents a new formula for recurved walls which can be used to estimate the overtopping flow rates reduction compared to normal vertical parapets. The formula has been obtained for vertical breakwaters by using numerical computations. The recurved parapet has the shape of a circumference sector, characterized by a radius and an opening angle. The numerical computations were performed applying OpenFOAM ${ }^{\mathbb{R}}$ which solves the 3D RANS equations for multiphase flows (air and water). The results show the high hydraulic efficiency of recurved walls in reducing overtopping rates compared to traditional vertical parapets.
\end{abstract}

Keywords: recurved parapet walls, wave overtopping, terminals workability, vertical breakwaters.

\section{INTRODUCTION}

The main function of port breakwaters is to protect harbour basins from incoming waves and currents. The protection has to ensure moored ships movements small enough to allow safe loading and unloading operations and to limit the influence of the same ships movements on the terminal workability.

A general rule of port planning excludes, or at least does not recommend, to place maritime terminals along the inner side of main breakwaters for safety reasons. Indeed, main breakwaters are exposed to the direct action of incoming waves and therefore they may be subjected to wave overtopping which can significantly reduce the workability of terminals placed along their inner side. For the general framework of wave overtopping of sea defence and related structures, the reader can refer to EurOtop [1].

Despite this rule, main breakwaters are very often used in the Mediterranean Sea to host maritime terminals mainly for two reasons:

i) along the internal side of these structures there are the higher natural port depths, that are suitable to moor large ships;

ii) usually main breakwaters are very long and therefore offer the opportunity to host along their inner side, long quays.

A general approach normally used to reduce wave overtopping and therefore to increase the workability of these terminals, consists in realizing high parapet walls (crownwalls). In order to limit the height of these parapets to contain their visual impact, a very efficient 
solution is to use recurved parapets. Using this approach, the seaward side of the top profile of the crownwall is shaped to form an overhang (recurved parapet/wave return wall/bullnose) aimed at further reducing wave overtopping by deflecting back seaward the uprushing water, as described by Castellino [2].

An example of such a situation is provided by the cruise terminal of the Port of Civitavecchia (Italy) whose geographical location is reported by Fig. 1. The cruise terminal, shown in detail in Fig. 2, is positioned in the inner side of the main port breakwater which is made by a vertical structure. The high water depth in front of the vertical breakwater, in order of $20.0 \mathrm{~m}$ below the m.s.l., favors wave overtopping which could reduce the workability of the terminal located behind the parapet wall. In order to reduce wave overtopping without increasing excessively the height of the wall, a recurved parapet wall has been used as shown in Fig. 3. The recurved wall has the shape of a quarter of a circumference with a radius of $1.5 \mathrm{~m}$.

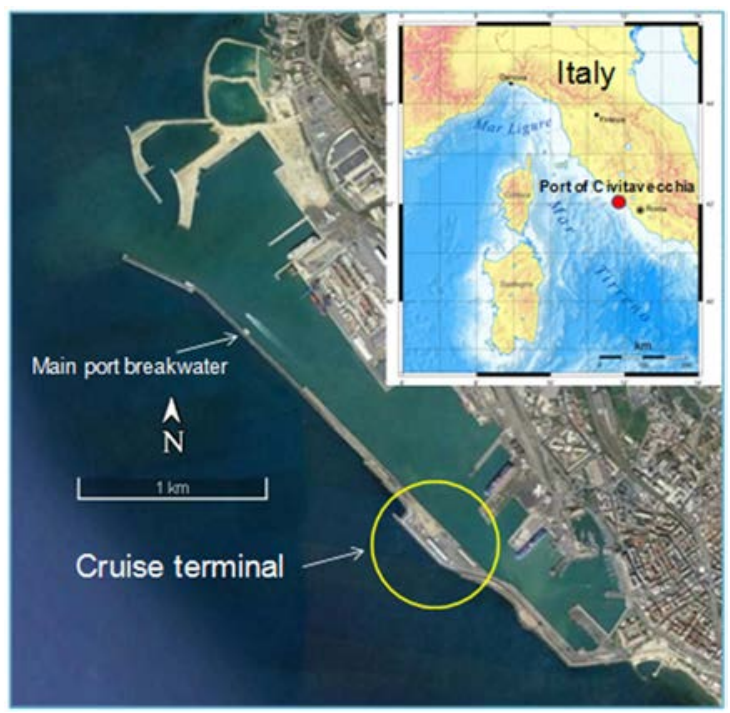

Figure 1: Location of the Cruise terminal on the inner side of the main vertical breakwater of the Port of Civitavecchia (Italy).

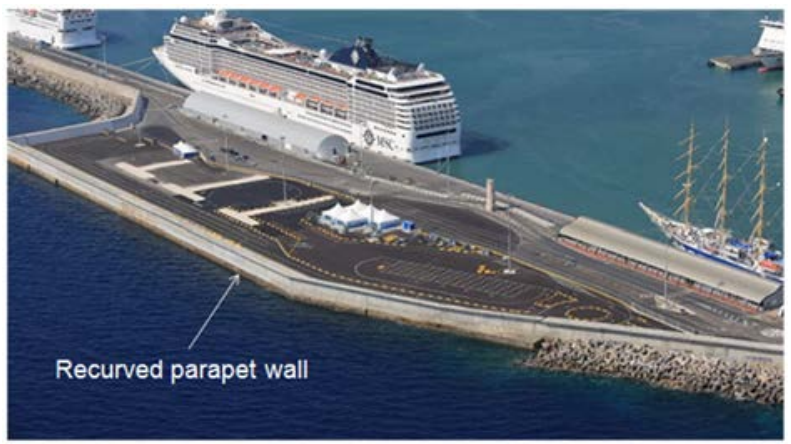

Figure 2: Detail of the Cruise terminal of the Port of Civitavecchia (Italy). 


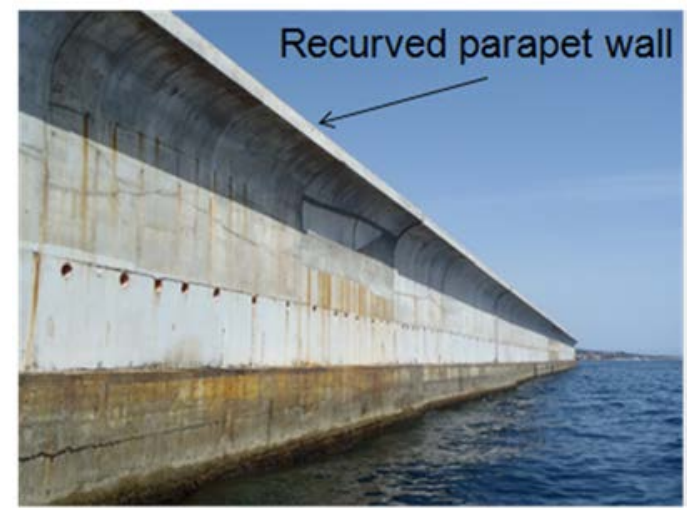

Figure 3: Detail of the recurved parapet wall.

The aim of the present paper is to provide a new formula for recurved walls placed on vertical breakwaters, which can be used to estimate the overtopping flow rates reduction compared to normal vertical parapets. The new formula has been obtained by using numerical simulations based on the application of OpenFOAM ${ }^{\circledR}$ which solves the 3D RANS equations for a multiphase flows (air and water). As described below, the influence of the main variables governing the physical phenomena, has been analyzed using a parametric approach in order to provide usable results for the design of these type of structures. In the first paragraph of the paper, the description of the numerical simulations together with the used geometries and the considered incoming wave conditions are provided. In the second paragraph the obtained results are presented and discussed.

\section{DESCRIPTION OF THE NUMERICAL SIMULATIONS}

In Fig. 4 the geometrical setup is shown. The numerical wave flume dimensions (left panel of Fig. 4) are the same of those of Castellino et al. [3]: the length is of $100.0 \mathrm{~m}$ and the constant water depth $\mathrm{h}$ is $20.0 \mathrm{~m}$. The wave generation is placed on the west side of the flume. The parapet wall freeboard is $R_{c}=6.5 \mathrm{~m}$. The recurved parapet (right panel of Fig. 4) has the shape of a circumference sector, characterized by the radius $r$ and the opening angle $\alpha$ and therefore the overhang 1 is given by $\mathrm{l}=\mathrm{r}(1-\cos \alpha)$. The parapet was simulated by using two geometries: the curved one and the vertical one without the curved part (dotted part of the figure). The two geometries were compared assuming for both the same value of $\mathrm{R}_{\mathrm{c}}$.

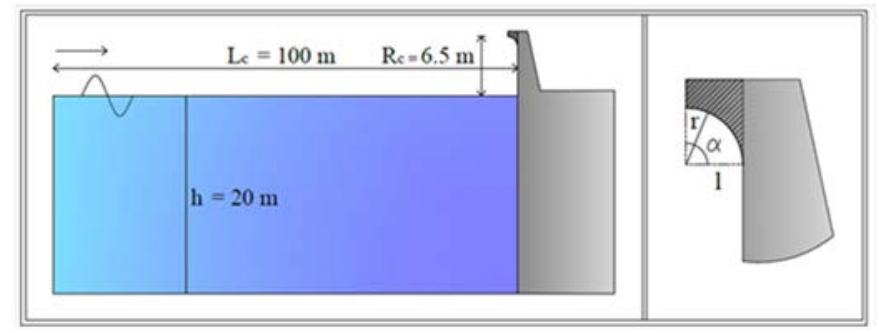

Figure 4: Geometrical configuration of the numerical wave flume (left panel) and of the recurved parapet wall (right panel). The vertical wall has been simulated excluding the dotted part of the figure in the right panel. 
For the recurved parapet the variation of both the parameters $r$ and $\alpha$ has been taken into consideration as shown in Fig. 5. The opening angle ranges between $0^{\circ}$ (vertical parapet wall) and $90^{\circ}$ (with the two intermediate angles equal to $45^{\circ}$ and $70^{\circ}$ ), while for the radius the three values $1.0 \mathrm{~m}, 1.5 \mathrm{~m}$ and $2.0 \mathrm{~m}$ have been considered.

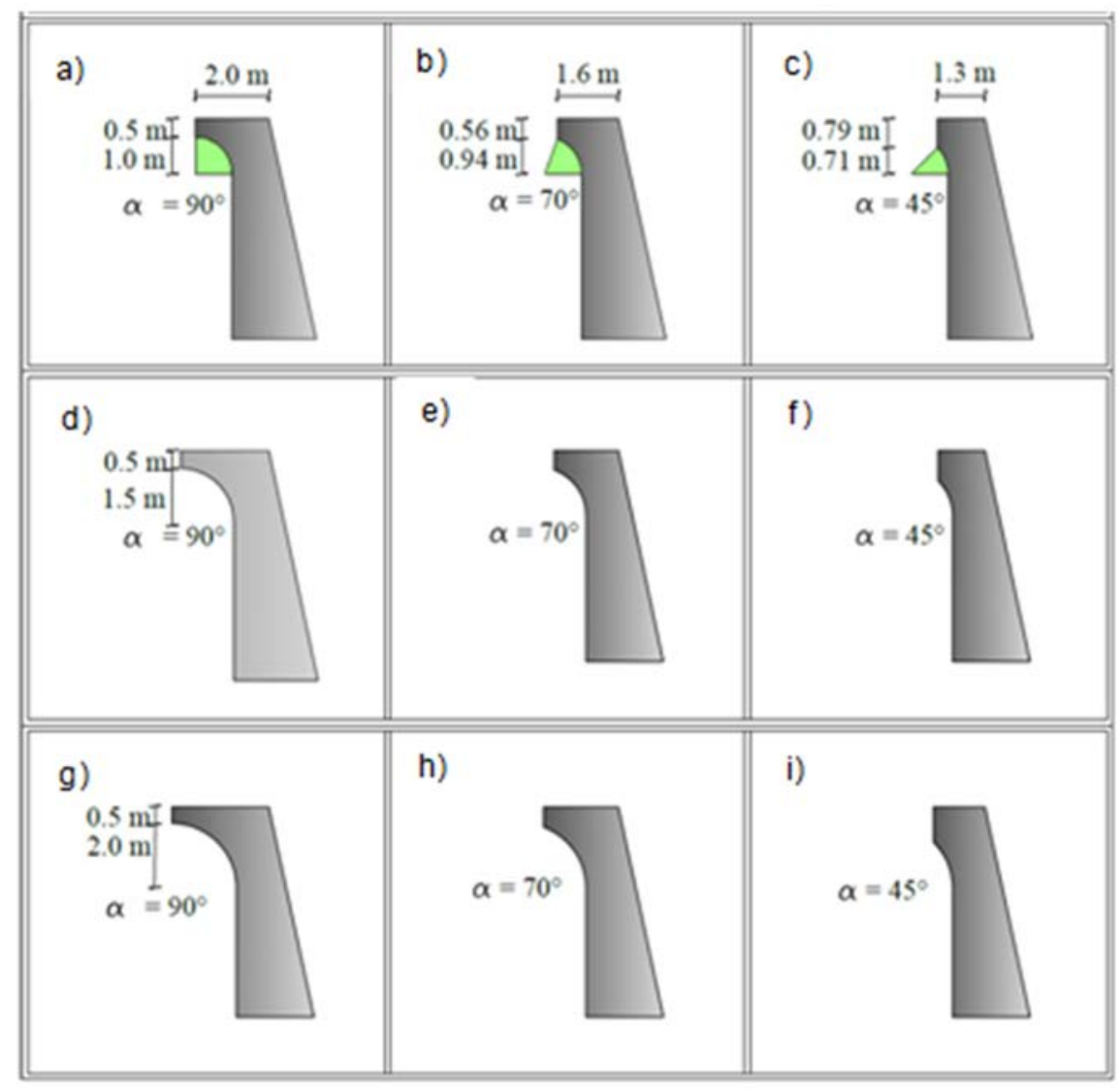

Figure 5: Geometric configurations examined for the recurved parapet.

Numerical simulations have been performed by using IHFOAM (Higuera et al. [4]; Higuera et al. [5]) to analyze the results obtained in terms of wave overtopping. The chosen tool is an extension library working in the interFOAM solver, which is based on the 3D RANS eqns for a multiphase flow (air and water). Both the phases are considered incompressible. The 3D RANS eqns, coupled to the VOF eqn, reads as follows:

$$
\begin{gathered}
\frac{\partial u_{i}}{\partial x}=0 \\
\frac{\partial \rho u_{i}}{\partial t}+\frac{\partial \rho u_{i} u_{j}}{\partial x_{j}}-\frac{\partial}{\partial x_{j}}\left[\mu_{e f f} \frac{\partial u_{i}}{\partial x_{j}}\right]=-\frac{\partial p^{*}}{\partial x_{i}}+F_{b, i}+F_{\sigma, i}, \\
\frac{\partial \alpha}{\partial t}+\nabla \cdot(U \alpha)+\nabla \cdot\left(\alpha(1-\alpha) U_{c}\right)=0,
\end{gathered}
$$


where $u$ represents the velocity, $p$ the pressure, $F_{b, i}$ the viscose and turbulence stresses. $F_{s, i}$ is the surface tension, $U_{c}$ is an artificial compression vector to preserve a sharp interface between air and water, $\alpha$ is the phase fraction, $\rho$ is the water density, $U$ is the velocity vector.

Furthermore, the discretization of the domain by using OpenFOAM ${ }^{\circledR}$ allows to perfectly describe the recurved shape of the wall. This is due to the body-fitted method adopted in the numerical model. An example of the adopted discretization is illustrated in Fig. 6.

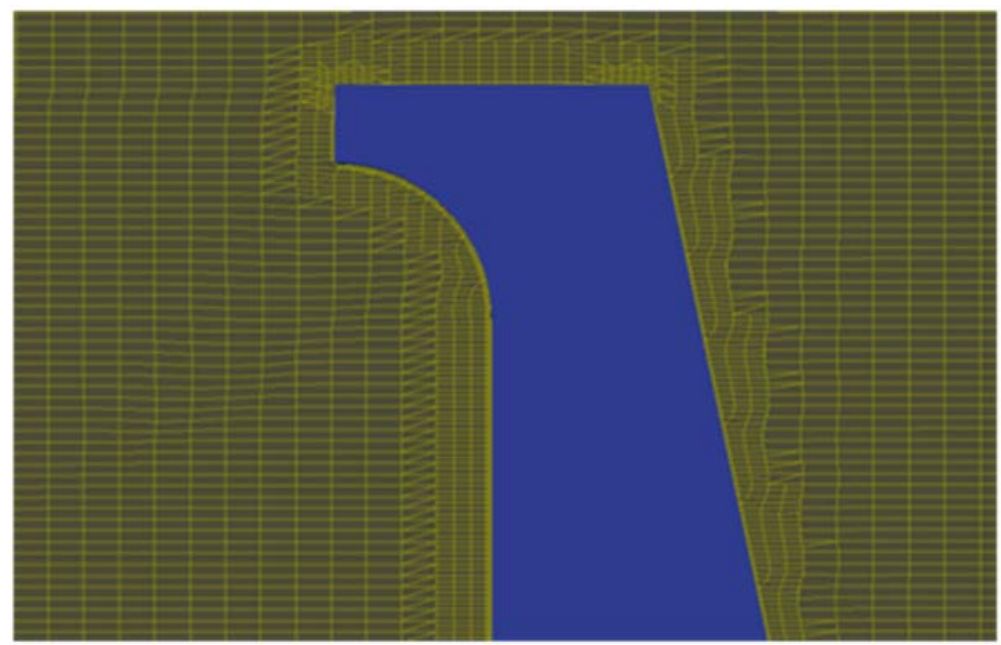

Figure 6: Example of mesh adopted in OpenFOAM ${ }^{\circledR}$ to discretize the recurved parapet wall.

Non-breaking regular and irregular wave conditions have been performed varying both the wave height and period. The incoming wave characteristics are listed in Table 1, where $H$ and $T$ are respectively the wave height and the period of regular waves and $H_{s}$ and $T_{p}$ are the significant wave height and the peak period of irregular waves. Irregular waves were simulated using the technique described by Castellino et al. [3].

Table 1: Characteristics of the wave conditions performed. Regular (left) and irregular (right) waves.

\begin{tabular}{|c|c|c|c|c|}
\hline & $\mathrm{H}(\mathrm{m})$ & $\mathrm{T}(\mathrm{s})$ & $\mathrm{H}_{\mathrm{s}}(\mathrm{m})$ & $\mathrm{T}_{\mathrm{p}}(\mathrm{s})$ \\
\hline W4 & 4.0 & 8.0 & 2.1 & 8.0 \\
W5 & 5.0 & 8.0 & 2.7 & 8.0 \\
W6 & 6.0 & 8.0 & 3.2 & 8.0 \\
W7 & 7.0 & 11.0 & 3.8 & 11.0 \\
W8 & 8.0 & 13.0 & 4.3 & 13.0 \\
\hline
\end{tabular}

All the wave conditions of Table 1 have been also reproduced for a "traditional" vertical parapet, characterized by an opening angle equal to $0^{\circ}$.

For a complete description of the technique used in numerical simulations and for the verification of numerical results performed also experimentally, the reader can refer to Castellino [2], Castellino et al. [6] and Martinelli et al. [7]. 


\section{RESULTS AND DISCUSSIONS}

The results of the numerical simulations are here presented in terms of wave overtopping. The excellent hydraulic performance of the recurved parapet wall with respect to the vertical one is, clearly shown as an example by Fig. 7, where the free surface elevations computed for the vertical parapet (left panel) and for the recurved wall (right panel) are compared in the instant in which the maximum overtopping volume take places for the vertical parapet. The two numerical simulations shown by Fig. 7 are characterized by the same incoming wave conditions and the same parapet freeboard. The recurved parapet reduce the wave overtopping (in this case it cancels it) by deflecting back seaward the uprushing water.
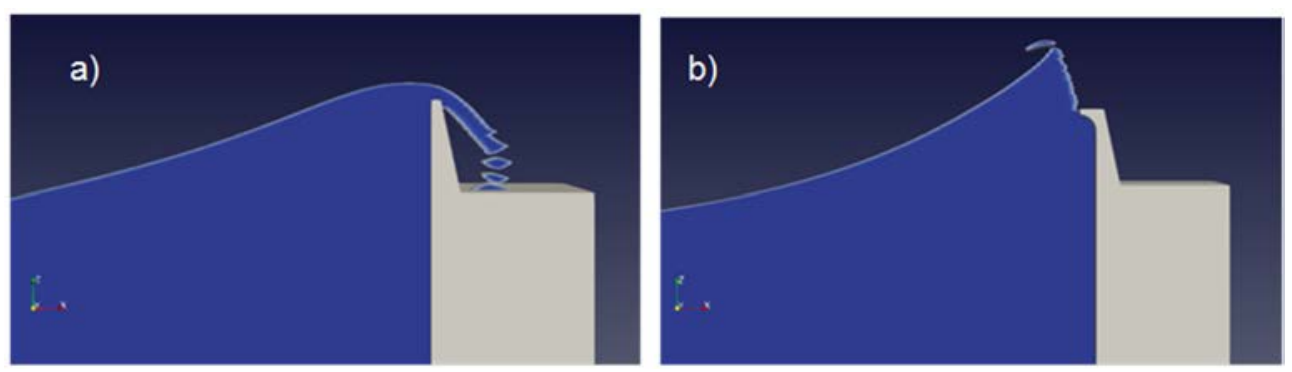

Figure 7: Comparison of the free surface elevations computed for (a) the vertical parapet and (b) for the recurved wall. The two numerical simulations are characterized by the same incoming wave conditions and the same parapet freeboard.

It must be mentioned that the curved parapet generates also a wave impact on the underside part of the overhang. This wave impact produces impulsive pressures acting both on the overhang and on the vertical wall. These effects have been largely considered by the technical and scientific literature, which however has mainly dealt with the use of curved parapets or overhangs for seawalls. Seawalls are characterized by shallow water conditions at the toe of the structure and therefore the incoming waves are generally broken or nearly breaking. In these conditions the wave impact contribution of the overhang is not easily detectable. Only recently Castellino [2] and Castellino et al. [6] analyzed the wave impact on a recurved parapet of a vertical breakwater placed at a large water depth where the presence of broken or breaking waves can be excluded. They discovered a new physical phenomenon, named "confined-crest impact", which must be considered for the structural design of these curved walls.

The physical quantities here used to describe the reduction of wave overtopping discharges induced by recurved parapets with respect to vertical parapets, is the normalized wave overtopping ratio provided by $\mathrm{Q}_{\mathrm{R} \max } / \mathrm{Q}_{\mathrm{Vmax}}$ where:

i) $\quad Q_{R \max }$ is the maximum overtopping volume for the recurved parapet;

ii) $Q_{V \max }$ is maximum overtopping volume for the vertical configuration.

Wave overtopping depends mainly on:

i) the geometry of the parapet, which in the present case may be expressed by the overhang $\mathrm{l}=\mathrm{r}(1-\cos \alpha)$;

ii) the water depth $\mathrm{h}$;

iii) the wave steepness $\mathrm{s}=\mathrm{H} / \mathrm{L}_{0}$. 
These parameters may be expressed by using the non-dimensional variable $(1 / \mathrm{h}) \mathrm{s}$.

Expressing the wave steepness $\mathrm{s}$ by means of the ratio between the wave height $\mathrm{H}$ and the wavelength in deep water $\mathrm{L}_{\mathrm{o}}$, with $\mathrm{L}_{\mathrm{o}}=\mathrm{gT}^{2} / 2 \pi$ obtained by using the linear dispersion relation, the plot of Fig. 8 has been obtained.

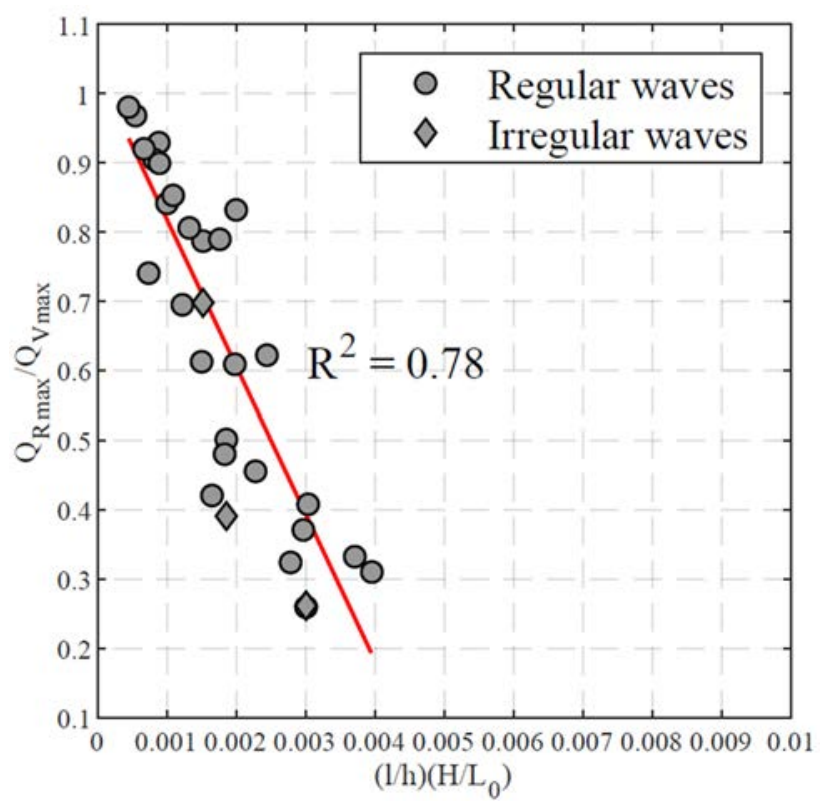

Figure 8: Normalized wave overtopping discharge $\mathrm{Q}_{\mathrm{Rmax}} / \mathrm{Q}_{\mathrm{Vmax}}$ as a function of the dimensionless parameter $(\mathrm{l} / \mathrm{h}) \mathrm{s}$, where $1, \mathrm{~h}$ and $\mathrm{s}$ represent the overhang, the water depth and the wave steepness respectively. The filled grey circles refer to regular waves results, while the filled grey diamonds refer to irregular waves.

In Fig. 8, where the dependence between $\mathrm{Q}_{\mathrm{Rmax}} / \mathrm{Q}_{\mathrm{Vmax}}$ and $(\mathrm{l} / \mathrm{h}) \mathrm{s}$ is represented, the filled grey circles refers to numerical simulations carried out by using regular waves for all the geometrical configurations of Fig. 5 and the filled grey diamonds refer to the irregular wave results obtained only for the configuration characterised by the radius $\mathrm{r}=1.0 \mathrm{~m}$ and the opening angle $\mathrm{a}=90^{\circ}$.

The red fitting curve of Fig. 8 is described by the following eqn:

$$
\frac{Q_{R \max }}{Q_{V \max }}=-211.9 \frac{l}{h} s+1.029,
$$

which is characterized by a standard deviation $\mathrm{R}^{2}=0.78$.

Wave overtopping has been numerically obtained by considering the vertical section localised on the tip seaward side of the parapet wall. Along this section, the vertical profile of the horizontal velocity component and the sea surface level has been measured for each time step, thus obtaining the overtopping volumes.

In Fig. 8 the high values of $(1 / h) s$ correspond to the geometrical configurations with the maximum value of the opening angle. These configurations are subjected to the minimum values of the wave overtopping but to the maximum loading conditions (see 
Castellino et al. [6]). The low values of $(1 / \mathrm{h}) \mathrm{s}$ refer to the parapet with $\mathrm{a}=45^{\circ}$ for which the maximum wave overtopping occurs together with the minimum loading conditions.

\section{CONCLUSIONS}

The reduction of the wave overtopping for a vertical breakwaters is very important in order to improve the workability of maritime terminals located in the inner side of these structures. A very efficient, cheap and with a limited visual impact solution is provided by recurved parapet walls. This kind of solution allows to deflect back seaward the incoming wave, reducing the required crest freeboard of the parapet walls. However, it has been shown by Castellino et al. [6], that a large force increase (named confined-crest impact) can be reached in these kind of configurations.

The overtopping reduction induced by a recurved wall, in the shape of a sector of circumference, with respect to a pure vertical wall has been studied within this paper. The analysis, carried out numerically, consists on a parametrization of the main physical quantities involved in the hydrodynamics. The wave overtopping reduction has a good correlation with the non-dimensional quantity $(1 / h)$ s describing the recurved shape, the wave steepness and the water depth. The results show a decrease of the wave overtopping, increasing the opening angle of the recurved wall.

\section{ACKNOWLEDGEMENT}

The present research has been founded by "Sapienza" University of Rome in the contest of the call: "Progetti Piccoli" 2016.

\section{REFERENCES}

[1] van der Meer, J.W. et al., Manual on wave overtopping of sea defences and related structures. Manual for EurOtop, www.overtopping-manual.com, 2018.

[2] Castellino, M., Impulsive forces induced by non-breaking waves on vertical structures with recurved parapets. PhD thesis, "Sapienza" University of Rome, Italy, 2019.

[3] Castellino, M., Lara, J.L., Romano, A., Losada, I.J. \& De Girolamo, P., Wave loading for recurved parapet walls in non-breaking wave conditions: Analysis of the induced impulsive forces. Proceedings of the 36th Conference on Coastal Engineering, 2018.

[4] Higuera, P., Lara, J.L. \& Losada, I.J., Realistic wave generation and active wave absorption for Navier-Stokes models: Application to OpenFOAM ${ }^{\circledR}$. Coastal Engineering, 71, pp. 102-118, 2013.

[5] Higuera, P., Lara, J.L. \& Losada, I.J., Simulating coastal engineering processes with OpenFOAM $^{\circledR}$. Coastal Engineering, 71, pp. 119-134, 2013.

[6] Castellino, M. et al., Large impulsive forces on recurved parapets under non-breaking waves: A numerical study. Coastal Engineering, 136, pp. 1-15, 2018.

[7] Martinelli, L. et al., Experimental investigation on non-breaking wave forces and overtopping at the recurved parapets of vertical breakwaters. Coastal Engineering, 141, pp. 52-67, 2018. 